\title{
ARDL Method: Forecasting Data Kemiskinan di NTB
}

\author{
${ }^{1}$ Aulia Rahmasari, ${ }^{2}$ Eka Hawari S., ${ }^{3}$ Miftahul Jannah, ${ }^{4}$ Pathullaili, ${ }^{5}$ Linda Kurnia, ${ }^{6}$ Ahmad Satria \\ 1,2,3,4,5,6 Tadris Matematika, Universitas Islam Negeri Mataram, Indonesia \\ 1110103008.mhs@uinmataram.ac.id, ${ }^{2} 170103009 . m h s @ u i n m a t a r a m . a c . i d, 3170103010 . m h s @ u i n m a t a r a m . a c . i d$,

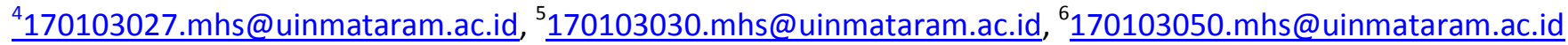

\begin{abstract}
INFO ARTIKEL
Riwayat Artikel:

Diterima: 23-03-2019

Disetujui: 30-04-2019

\section{Kata Kunci:}

Forecasting,

ARDL,

Kemiskinan

\section{ABSTRAK}

Abstrak:Penelitian ini bertujuan untuk memprediksi data Jumlah penduduk miskin di Provinsi Nusa Tenggara Barat (NTB) tahun 2019 dengan menggunakan metodeAutoregressive Distributed Lag (ARDL). Jenis penelitian ini merupakan penelitian kuantitatif. Data yang digunakan dari tahun 2002-2018, dengan parameter error MAD, MSE, MRSE dan MAPE. Berdasarkan hasil simulasi data diperoleh hasil prediksi tahun 2019 jumlah penduduk miskin di NTB sebesar 718.059 jiwa, dengan nilai MAD sebesar 4.040,26667, MSE sebesar 1.943.057.717, MRSE sebesar 44.080,1284 dan MAPE sebesar 3\%.
\end{abstract}

\section{Keywords:}

Forecasting,

$A R D L$,

Poor People

Abstract:This study aims to predict data on the number of poor people in the Province of West Nusa Tenggara (NTB) in 2019 by using the Autoregressive Distributed Lag (ARDL) method. This type of research is quantitative research. Data used from 20022018. With MAD, MSE, MRSE and MAPE error parameters. Based on the data simulation results obtained in 2019 prediction results the number of poor people at NTB is 718,059 people, with $M A D$ value of 4,040,26667, MSE of 1,943,057,717, MRSE of 44,080, 1284 and MAPE of $3 \%$.

\section{d.) 8 Crossref}

\section{A. LATAR BELAKANG}

Kehidupan manusia sehari-hari tidak akanpernah lepas dari pengamatan. Ketika seseorang melihat atau mengamati suatu kejadian dalam suatu waktu sering timbul pertanyaan apa yang akan terjadi pada waktu yang akan datang dan bagaimana kejadian pada waktu sebelumnya. Begitu pula saat mengamatihubungan pendapatan dan ketersediaan kebutuhan dasar di NTB dengan jumlah kemiskinan yang ada pada NTB, makaakan muncul pertanyaan apa yang terjadi di daerah tersebut. Pertanyaan menyangkut waktu tersebut mendasari munculnya suatu kajian runtun waktu (time series analysis).

Runtun waktu merupakan serangkaian pengamatan terhadap suatu peristiwa, kejadian, yang diambil dari waktu ke waktu, serta dicatat secara teliti berdasarkan urutan waktu, kemudian disusun sebagai data statistik (Rizcka Indah Hani Pratama, 2018: 490).Analisis runtun waktu merupakan analisis sekumpulan data dalam suatu periode waktu yang lampau yang berguna untuk mengetahui atau meramalkan kondisi masa mendatang. Hal ini didasarkan bahwa perilaku manusia banyak dipengaruhi kondisi atau waktu sebelumnya sehingga dalam hal ini faktor waktu sangat penting peranannya (Aidah,2011: II-6).

Banyak jenis metode peramalan yang tersedia.Namun, yang lebih penting adalah bagaimana memahami karakteristik suatu metode peramalan agar sesuai dengan situasi pengambilan keputusan. (Andri Hendriana, 2011: 1)

Pada model regresi yang memasukan nilai variabel yang menjelaskan nilai masa kini atau nilai masa lalu dari variabel bebas sebagai tambahan pada model yang memasukkan lag dari variabel tak bebas sebagai salah satu variabel penjelas disebut Autoregressive Distributed Lag (ARDL) yang merupakan model dinamis dalam ekonometrika. Ekonometrika sendiri merupakan suatu ilmu yang menganalisis fenomena ekonomi dengan menggunakan teori ekonomi, matematika, dan statistika, yang berarti teori ekonomi tersebut dirumuskan melalui hubungan matematika kemudian diterapkan pada suatu data untuk dianalisis menggunakan metode statistika. 
Keistimewaan dari model dinamis autoregressive dan model dinamis distribusi lag adalah model tersebut telah membuat teori statis menjadi dinamis karena model regresi yang biasanya mengabaikan pengaruh waktu, melalui model autoregressive dan model distribusi lag waktu ikut diperhitungkan (Dewi Yuliastuti Tulak, 2017 : 314). Oleh karena itu, model autoregressive dan model dinamis distribusi lag sering disebut satu rangkaian dengan namaAutoregressive dan Distribusi Lag.

\section{B. TINJAUAN PUSTAKA}

Metode ARDL pertama kali diperkenalkan oleh Pesaran dan Shin (1997) dengan pendekatan uji kointegrasi dengan pengujian Bound TestCointegration (Deni Apriyanto, 2016 : 14). Model ADL dapat disingkat dengan model ARDL.Metode ARDL merupakan salah satu bentuk metode dalam ekonometrika. Metode ini dapat mengestimasi model regresi linear dalam menganalisis hubungan jangka panjang yang melibatkan adanya uji kointegrasi diantara variabel-variabel times series (H. Elkadhi, R. Hamida, 2014 : 1).

ARDL adalah metode regresi yang memasukkan lag dari kedua variabel dependen dan independen secara bersamaan. Dengan menggunakan model ini, kita bisa menganalisis hubungan jangka panjang ketika variabel-variabel penjelasnya campuran antara yang bersifat 1(1) dan 1(0). Estimator ARDL akan menghasilkan koefisien jangka panjang yang konsisten yang dapat dibuat dengan menggunakan standard normal asymplotic theory..Salah satu keunggulan dari pendekatan ARDL ini adalah menghasilkan estimasi yang konsisten dengan koefisien jangka panjang yang bagus tanpa peduli apakah variabel-variabel penjelasnya atau regresornya $1(0)$ ataupun $1(1)$. Dalam kasus adanya jangka ppanjang yang bersifat trend stationarity, dengan ARDL dapat dilakukan detrending terhadap series dan memodelkan detrended series tersebut sebagai distributed lag yang stasioner. (Nur Fadhilah, 2017:835).

Model AR adalah model yag menggunakan satu atau lebih data masa lampau dari varabel dependen diantara variabel penjelas. Model DL adalah model regresi melibatkan data pada waktu sekarang dan waktu masa lampau (lagged) dari variabel penjelas (Gujarati \& Porter, 2010 : 22).

Model ARDL sangat berguna dalam ekonometrik empiris, karena membuat teori ekonomi yang bersifat statis menjadi dinamis dengan memperhitungkan peranan waktu secara explisit. Model ini dapat membedakan respon jangka pendek dan jangka panjang dari variabel tak bebas terhadap satu unit perubahan dalam nilai variabel penjelas (Gujarati, 2012 : 23).

Keistimewaan dari model autoregressive dan model distribusi lag adalah model tersebut membuat teori statis menjadi dinamis karena model regresi yang biasanya mengabaikan pengaruh waktu, melalui model autoregressive dan model distribusi lag, waktu ikut diperhitungkan dan panjang beda kala (lag) diketahui (Gujarati, 2014 : 23).

Distribution lag model adalah model regresi yang tidak hanya mencakup nilai sekarang tetapi juga nilai masa lalu (lag) dari variabel penjelas (X) sedangkan autoregressive distributed lag adalag model yang mencakup saru atau lebih nilai masa lalu (lag) dari variabel terkait antara variabel penjelasnya. "Model regresi yang memasukkan nilai variabel yang menjelaskan nilai masa kini atau nilai masa lalu (lag) dari variabel tak bebas sebagai salah satu variabel penjelas disebut autoregressive distributed lag (ARDL). Model ini dapat membedakan respon jangka pendek dan jangka panjang dari variabel tak bebas terhadap suatu unit perubahan dalam nilai variabel penjelas" (Gujarati, 2014: 144).

Formula yang dapat diterapkan pada Metode Autoregressive Distributed Lag:

Rumus formula apabila menggunakan 1 data :

$$
X=\beta_{0}+\phi_{1} X_{t-1}
$$

Rumus formula apabila menggunakan 2 data :

$$
X=\beta_{0}+\phi_{1} X_{t-1}+\ldots .+\phi_{p} X_{t-p}+\beta_{0} Y_{t}+\ldots .+\phi_{q} Y_{t-q}
$$

Dimana $X$ adalah stasionertingkat level / variabel terikat, $\beta_{0}$ adalah konstanta, $\phi_{1}$ adalah koefisien dependent, $X_{t-1}$ adalah variabel waktu sebelumnya, $t-1$ adalah waktu sebelumnya, $t$ adalah waktu, dan $Y_{t-1}$ adalah variable data kedua waktu sebelumnya.

Beberapa penelitian sebelumnya menujukkan hasil yang bervariasi untuk dapat digunakan sebagai dasar penelitian dan bahan kajian penelitian yang dilakukan.Deni Apriyanto (2016) melakukan penelitian menggunakan metode ARDL berupa data historis kurs Yen, kurs Euro dan kurs Dolar terhadap harga saham PT. Astra Internasional TBK.Dari hasil pengujian, tidak terdapat kointegrasi antar variabel dan hasil menunjukan bahwa variabel yang berpengaruh signifikan terhadap harga saham adalah harga saham pada dua hari sebelumnya, kurs dolar pada dua hari sebelumnya dan kurs yen pada pada hari tersebut.

Dewi Yuliastuti (2017) melakukan penelitian menggunakan ARDL.Data yang digunakan dalam penelitian beliau adalah data historis sekunder kelompok bahan makanan dan kelompok makanan jadi terhadap inflasi. Adapun hasil penelitian beliau variabel bahan makanan secara parsial berpengaruh negatif dan signifikan terhadap laju inflasi kota Palu.

Dari beberapa referensi penelitian terdahulu maka peneliti tertarik melakukan penelitian terhadap data Jumlah Kemiskinan Penduduk Provinsi Nusa Tenggara Barat (NTB) menggunakan ARDL dengan 
variabel independen yakni data Jumlah Kemiskinan Penduduk Provinsi Nusa Tenggara Barat (NTB)

\section{METODE PENELITIAN}

Data yang dipakai dalam penelitian ini adalah data time series periode tahunan selama 17 tahun, dimulai dari tahun 2002 sampai tahun 2018, dengan total data sebanyak 15.225.517, yaitu data kemiskinan. Data kemiskinan ini diambil dari website https://ntb.bps.go.id.Ujikointegrasi dilakukan untuk melihat apakah ada hubungan jangka panjang antara variabel bebas dan variabel terikat, setelah itu menentukan selang optimal yaitu menentukan lag dari data. Selanjutnya melakukan regression dari excel untuk menentukan peramalan tahun selanjutnya, kemudian menentukan error dari data yang tersedia, lalu membuat grafik dari data aktual dan data prediksi. Langkah-langkah dalam penelitian ini dapat dilihat pada Gambar 1 dibawah ini.

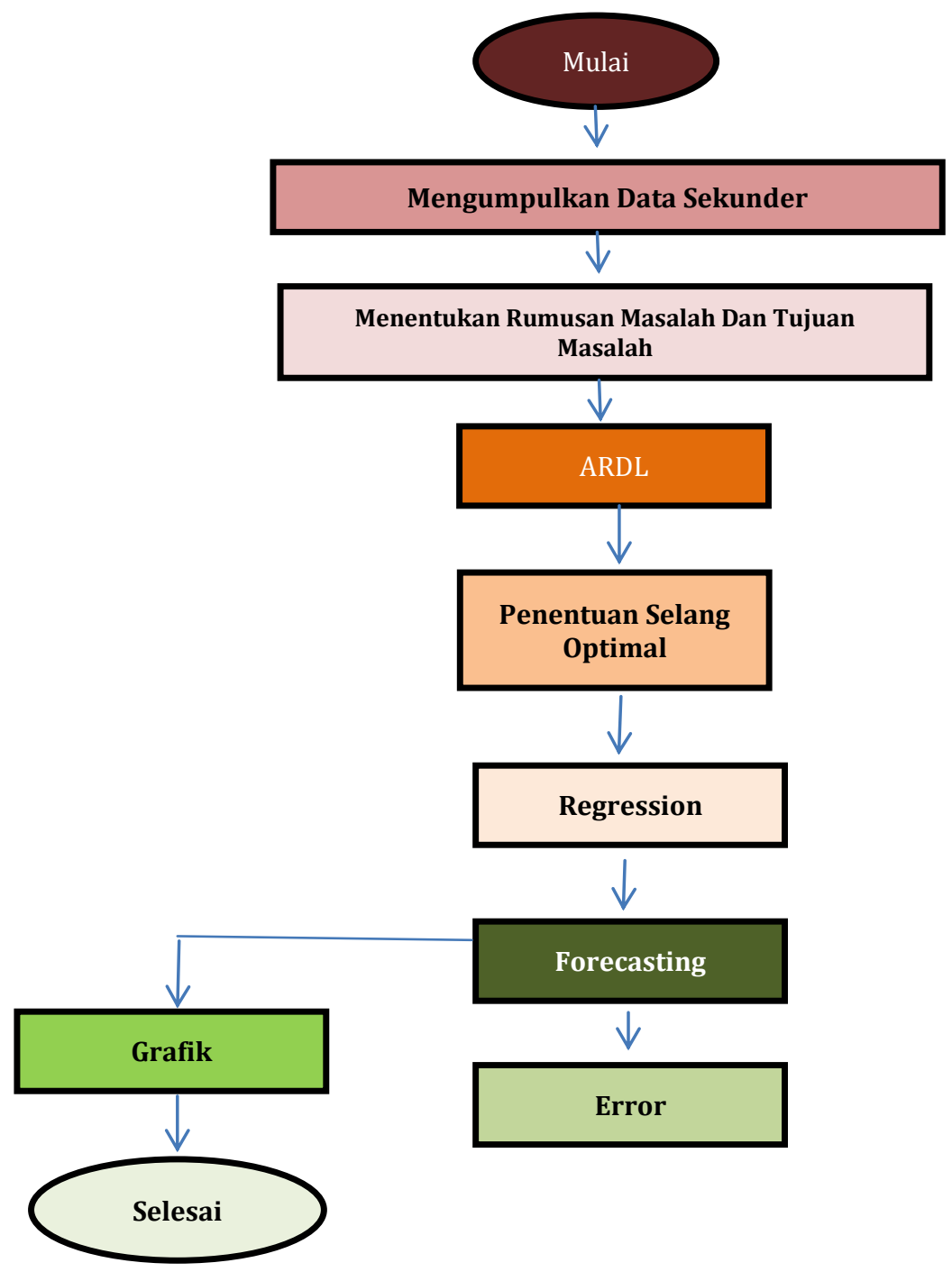

Gambar 1. Prosedur Penelitian

\section{HASIL DAN PEMBAHASAN}

Menghitung peramalan (forecast)danerror dari data jumlah penduduk miskin tahun 2002 sampai dengan tahun 2018 dengan menggunakan metode Autoregressive Distributed Lag (ARDL)untuk memprediksi tahun 2019.

1. Menentukan Lagdari data

Tabel 1. Menentukan Lag

\begin{tabular}{ccc}
\hline Tahun & $\mathbf{X}_{\mathbf{t}}$ & $\mathbf{X}_{\mathbf{t}-1}$ \\
\hline 2002 & 1.145 .081 & $*$ \\
\hline
\end{tabular}

\begin{tabular}{ccc}
\hline Tahun & $\mathbf{X}_{\mathbf{t}}$ & $\mathbf{X}_{\mathbf{t}-\mathbf{1}}$ \\
\hline 2003 & 1.054 .740 & 1.145 .081 \\
\hline 2004 & 1.031 .605 & 1.054 .740 \\
\hline 2005 & 1.136 .524 & 1.031 .605 \\
\hline 2006 & 1.156 .144 & 1.136 .524 \\
\hline 2007 & 1.118 .452 & 1.156 .144 \\
\hline 2008 & 1.080 .613 & 1.118 .452 \\
\hline 2009 & 1.050 .948 & 1.080 .613 \\
\hline 2010 & 1.009 .352 & 1.050 .948 \\
\hline 2011 & 900.573 & 1.009 .352 \\
\hline
\end{tabular}




\begin{tabular}{|c|c|c|}
\hline Tahun & $\mathbf{X}_{\mathrm{t}}$ & $\mathbf{X}_{\mathrm{t}-\mathbf{1}}$ \\
\hline 2012 & 862.516 & 900.573 \\
\hline 2013 & 843.660 & 862.516 \\
\hline 2014 & 820.818 & 843.660 \\
\hline 2015 & 823.886 & 820.818 \\
\hline 2016 & 804.450 & 823.886 \\
\hline 2017 & 793.776 & 804.450 \\
\hline 2018 & 737.460 & 793.776 \\
\hline
\end{tabular}

2. Menentukan nilai intercept dan nilai variabelnya Berdasarkan hasil analisa data sehingga diperoleh output pada Tabel 2 .

Tabel 2. Hasil Output

SUMMARY OUTPUT

\begin{tabular}{lr}
\hline \multicolumn{2}{c}{ Regression Statistics } \\
\hline Multiple R & 0.94348261 \\
R Square & 0.890159435 \\
Adjusted R Square & 0.88231368 \\
Standard Error & 48416.96335 \\
Observations & 16 \\
\hline
\end{tabular}

Tabel SummaryOutput(Tabel

2) di atasmenjelaskan kekuatan hubungan antara model (variabel bebas) dengan varibel terikat .Multiple $R(\mathrm{R}$ majemuk) adalah suatu ukuran untuk mengukur tingkat (keeratan) hubungan linear antara variabel terikat dengan selluruh varibel bebas secara bersama-sama. Pada kasus dua variabek(satu varibel terikat dan satu varibel bebasa), besaran $r$ (bisa ditulkan dengan hurf kecil untuk varibel ) dapat bernilai positif maupun negatif (antara -1-1), tetapi untuk lebih dari dua varbel, besaran R selalu bernilai positif(antara 0-1). Nilai R yang lebih besara (+ atau ) menunjukkan yang lebih kuat.

$R$ square sering disebut dengan koefisien determinasi, adalah mengukur kebaikan Suai(goodness of fit) dari persaaman regresi yaitu membeikan proforsi atau persentase pariasi total dalam variabel terikat yang dijelaskan oleh variabel bebas. Adjusted $R$ square adalah fungsi yang tidak pernah menurun dari banyaknya variabel bebas yang ada dalam model.

Standard error merupakan standar eror dari estimasi variabel terikat,semakin kecil standar eror ini dibandingkan standar deviasi dari permintaan maka model regresi semakin tepat dalam memprediksi data.

Tabel 3. Tabel Output Perhitungan Anova

ANOVA

\begin{tabular}{|c|c|c|c|c|c|c|c|c|}
\hline & $D f$ & SS & $M S$ & $F$ & Significance F & & & \\
\hline Regression & 1 & $2.66 \mathrm{E}+11$ & $2.66 \mathrm{E}+11$ & 113.4575 & $4.25 \mathrm{E}-08$ & & & \\
\hline Residual & 14 & $3.28 \mathrm{E}+10$ & $2.34 \mathrm{E}+09$ & & & & & \\
\hline \multirow[t]{2}{*}{ Total } & 15 & $2.99 E+11$ & & & & & & \\
\hline & Coefficients & $\begin{array}{l}\text { Standard } \\
\text { Error }\end{array}$ & tStat & $P$-value & Lower 95\% & $\begin{array}{c}\text { Upper } \\
95 \%\end{array}$ & $\begin{array}{l}\text { Lower } \\
95.0 \%\end{array}$ & $\begin{array}{l}\text { Upper } \\
95.0 \%\end{array}$ \\
\hline Intercept & -703.8982 & 90219.61 & -0.0078 & 0.993885 & -194206 & 192797.9 & -194206 & 192797.9 \\
\hline X Variable 1 & 0.974646253 & 0.091502 & 10.65164 & $4.25 \mathrm{E}-08$ & 0.778394 & 1.170898 & 0.778394 & 1.170898 \\
\hline
\end{tabular}

Tabel 2 (analysis of variance) adalah menguji penerimaan (acceptability) model dari persfektif statistic dalam bentuk analisis sumber keragaman anova ini sering juga diterjemahkan sebagai analisis ragam.Degree of freedon $(\mathrm{dr})$ atau derajat bebas dari total adalan $\mathrm{n}-1$ dimana $\mathrm{n}$ adalah banyak observasi.

Sum of square (ss) atau jumlah kuadrat untuk regression diperolh dari penjumlahan kuadrat dari prediksi variabel terikat dikurangi dengan nilai ratarata data sebenarnya.Mean of square (MS) atau aratarata jumlah kuadrat. Nilai $F$ ini yang dikenal dengan $f$ hitung dalam pengujian hipotesa dibandingkan

Tabel 4. Menentukan Forecasting

\begin{tabular}{cccc}
\hline Tahun & $\mathbf{X}_{\mathbf{t}}$ & $\mathbf{X}_{\mathbf{t}-1}$ & Forecasting \\
\hline 2003 & 1.054 .740 & 1.145 .081 & $*$ \\
\hline 2004 & 1.031 .605 & 1.054 .740 & 1.027 .295 \\
\hline 2005 & 1.136 .524 & 1.031 .605 & 1.004 .746 \\
\hline 2006 & 1.156 .144 & 1.136 .524 & 1.107 .005 \\
\hline
\end{tabular}

dengan $\mathrm{f}$ tabel.Significance fmembandingklan antara taraf nyata dengan $f$ value atau signipicance $f$.

3. PerkiraanTahun Mendatang Menggunakan Rumus 1 di atas, maka diperolehperkiraan tahun 2019:

$=$ kolom dan baris pada nilai interecp + kolom dan baris pada X variable $1 *$ nilai jumlah pada tahun 2018

$$
\begin{aligned}
& X=-703,8983+0,974646 * 737.460 \\
& X=718.058,7 \\
& X=718.059
\end{aligned}
$$

\begin{tabular}{cccc}
\hline 2007 & 1.118 .452 & 1.156 .144 & 1.126 .128 \\
\hline 2008 & 1.080 .613 & 1.118 .452 & 1.089 .391 \\
\hline 2009 & 1.050 .948 & 1.080 .613 & 1.052 .512 \\
\hline 2010 & 1.009 .352 & 1.050 .948 & 1.023 .599 \\
\hline 2011 & 900.573 & 1.009 .352 & 983.057 \\
\hline 2012 & 862.516 & 900.573 & 877.036 \\
\hline
\end{tabular}


56 | Jurnal Teori dan Aplikasi Matematika (JTAM) | Vol. 3, No. 1, April 2019, Hal. 52-57

\begin{tabular}{llll}
\hline 2013 & 843.660 & 862.516 & 839.944 \\
\hline 2014 & 820.818 & 843.660 & 821.566 \\
\hline 2015 & 823.886 & 820.818 & 799.303 \\
\hline 2016 & 804.450 & 823.886 & 802.294 \\
\hline 2017 & 793.776 & 804.450 & 783.350 \\
\hline 2018 & 737.460 & 793.776 & 772.947 \\
\hline 2019 & & & 718.059
\end{tabular}

4. MenentukanParameter Error

Selanjutnya menentukan nilai error untuk mengetahui parameter keakuratan data, yang akan kita gunakan adalah Mean Absolute Deviation (MAD), Mean Square Error (MSE), Root Mean Squared Error (RMSE) dan Mean Absolute Percentage Error (MAPE). Formula yang dapat diterapkan dalam empat error tersebut antara lain:

$$
\begin{aligned}
& M A D=\frac{\sum_{t=1}^{n}\left|X_{t}-F_{t}\right|}{n} \\
& M S E=\frac{\sum_{t=1}^{n}\left(X_{t}-F_{t}\right)^{2}}{n} \\
& \text { RMSE }=\sqrt{\frac{\sum_{i=1}^{n}\left(X_{t}-F_{t}\right)^{2}}{n}} \\
& \text { MAPE }=\left(\frac{1}{n}\right) \sum_{t=1}^{n}\left|\frac{X_{t}-F_{t} \mid}{X_{t}}\right|
\end{aligned}
$$

Keterangan :

$X_{t}=$ data actual pada periode $\mathrm{t}$

$F_{t}=$ nilai peramalan pada periode $\mathrm{t}$

$n=$ jumlah data

Selesaikan satu persatu sehingga akan

\begin{tabular}{|c|c|c|c|c|c|c|c|}
\hline Tahun & $\mathbf{X}_{\mathrm{t}}$ & $\mathbf{X}_{\mathrm{t}-1}$ & $F_{t}$ & $X_{t}-F_{t}$ & $\left|X_{t}-F_{t}\right|$ & $\left(X_{t}-F_{t}\right)^{\wedge} 2$ & $\left|\left(X_{t}-F_{t}\right) / X_{t}\right|$ \\
\hline 2003 & 1.054 .740 & 1.145 .081 & 0 & 0 & 0 & 0 & 0 \\
\hline 2004 & 1.031 .605 & 1.054 .740 & 1.027 .295 & 4.310 & 4.310 & 18.576 .100 & 0,004177956 \\
\hline 2005 & 1.136 .524 & 1.031 .605 & 1.004 .746 & 131.778 & 131.778 & 17.365 .441 .284 & 0,115948277 \\
\hline 2006 & 1.156 .144 & 1.136 .524 & 1.107 .005 & 49.139 & 49.139 & 2.414 .641 .321 & 0,042502491 \\
\hline 2007 & 1.118 .452 & 1.156 .144 & 1.126 .128 & -7.676 & 7.676 & 58.920 .976 & 0,006863057 \\
\hline 2008 & 1.080 .613 & 1.118 .452 & 1.089 .391 & -8.778 & 8.778 & 77.053 .284 & 0,008123167 \\
\hline 2009 & 1.050 .948 & 1.080 .613 & 1.052 .512 & -1.564 & 1.564 & 2.446 .096 & 0,00148818 \\
\hline 2010 & 1.009 .352 & 1.050 .948 & 1.023 .599 & -14.247 & 14.247 & 202.977.009 & 0,014114997 \\
\hline 2011 & 900.573 & 1.009 .352 & 983.057 & -82.484 & 82.484 & 6.803.610.256 & 0,091590576 \\
\hline 2012 & 862.516 & 900.573 & 877.036 & -14.520 & 14.520 & 210.830 .400 & 0,01683447 \\
\hline 2013 & 843.660 & 862.516 & 839.944 & 3.716 & 3.716 & 13.808 .656 & 0,004404618 \\
\hline 2014 & 820.818 & 843.660 & 821.566 & -748 & 748 & 559.504 & 0,000911286 \\
\hline 2015 & 823.886 & 820.818 & 799.303 & 24.583 & 24.583 & 604.323 .889 & 0,029837866 \\
\hline 2016 & 804.450 & 823.886 & 802.294 & 2.156 & 2.156 & 4.648 .336 & 0,002680092 \\
\hline 2017 & 793.776 & 804.450 & 783.350 & 10.426 & 10.426 & 108.701 .476 & 0,013134688 \\
\hline 2018 & 737.460 & 793.776 & 772.947 & -35.487 & 35.487 & 1.259.327.169 & 0,048120576 \\
\hline 2019 & 0 & 0 & 772.947 & 0 & 0 & 0 & 0 \\
\hline \multirow[t]{5}{*}{ Total } & \multirow[t]{5}{*}{15.225 .517} & \multirow[t]{5}{*}{15633138} & 14883120 & 60.604 & \multirow[t]{5}{*}{60.604} & \multirow[t]{5}{*}{3.672 .844 .816} & \multirow[t]{5}{*}{0,400732298} \\
\hline & & & MAD & $4.040,26667$ & & & \\
\hline & & & MSE & 1.943 .057 .717 & & & \\
\hline & & & RMSE & $44.080,1284$ & & & \\
\hline & & & MAPE & $3 \%$ & & & \\
\hline
\end{tabular}
menghasilkan hasil error seperti pada Table 3 di bawah ini:

Tabel 5. Menentukan Forecasting 
5. Grafik Model Aktual dan Prediksi

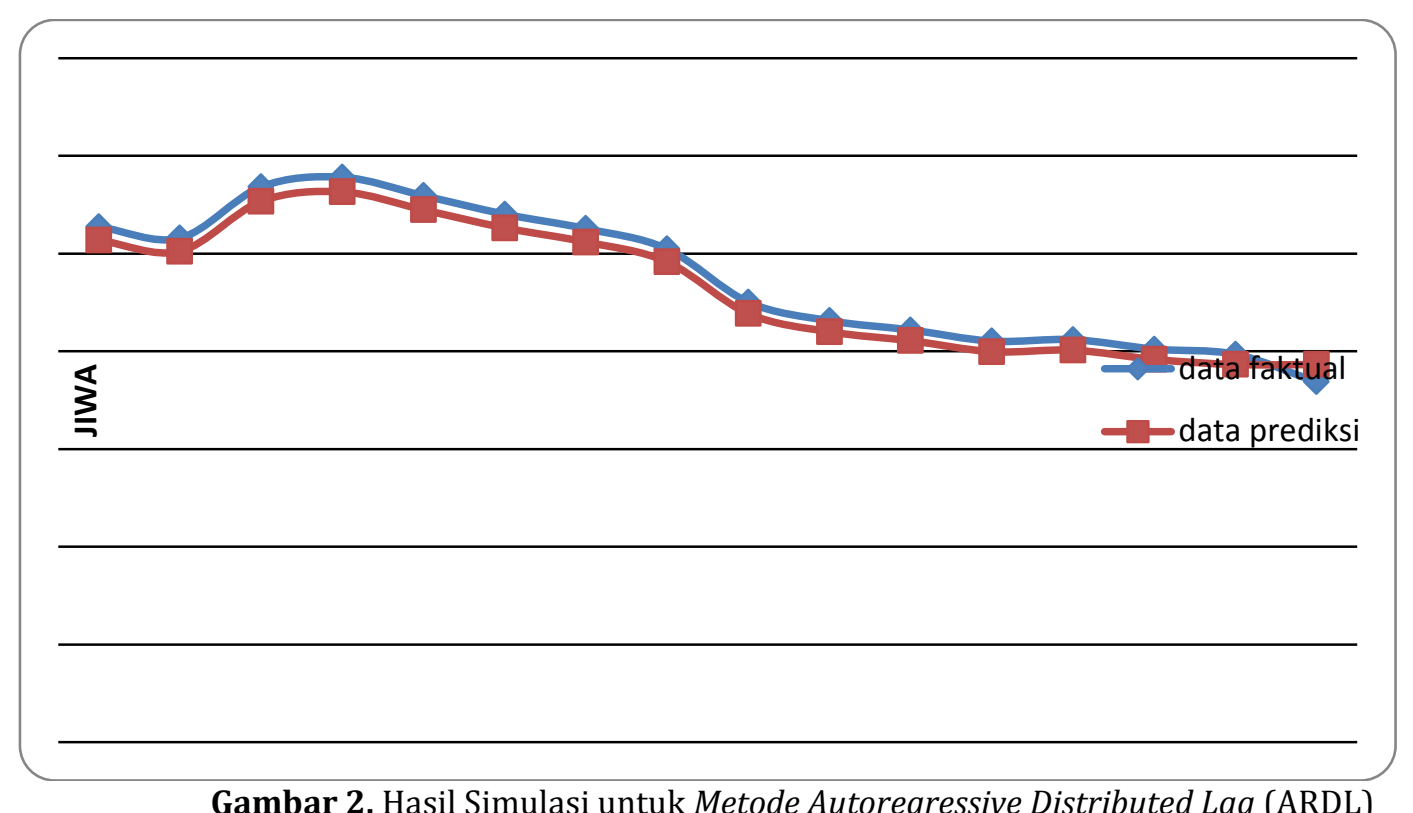

\section{E. SIMPULAN DAN SARAN}

Berdasarkan hasil simulasi di atas, kami memperoleh kesimpulan bahwa dari metode Autoregressive Distributed Lag yang digunakan dalam prediksi Data Jumlah Kemiskinan Penduduk Provinsi NTB tahun 2019 adalah sebesar 772.947dengan MAD, MSE, MRSE dan MAPE berturut turut sebesar $4.040,26667 ; 1.943 .057 .717 ; 44.080,1284$ dan 3\%.

Selanjutnya untuk menghitung peramalan atau memprediksikan suatu hal dalam ekonomi, statistik dan lain sebagainya, akan lebih baik apabila mencoba berbabagai macam metode dan menggunakan datadata yang lebih banyak lagi.untuk menemukan hasil yang paling akurat dari metode yang dilakukan.

\section{REFERENSI}

Aidah. (2011). Metode Time Series Autoregressive Untuk Peramalan Tingkat Inflasi Kota Pekanbaru. Skripsi

Apriyanto. D, (2016). Analisis Faktor-Faktor Yang Mempengaruhi Return Indeks Harga Saham Gabungan (Ihsg) Di Indonesia. Skripsi. Bogor

Fadhilah, N danSukmana, R. (2017). Pengaruh Sertifikat Bank Indonesia Syariah (SBIS) Jakarta Islamic Index (JII), Tingkat Inflasi, dan Index Harga Saham Gabungan (IHSG) Terhadap Nilai Tukar: Pendekatan Autoregressive Distributed Lag (ARDL), Jurnal Ekonomi Syariah Teori Dan Terapan, 4(1), 833-846

Gujarati, D dan Poter, Dawn, C. (2012). Dasar Ekonometrika Buku 2, Edisi Kelima. Jakarta:Salemba Empat.

Gujarati, D. (2014). Dasar-Dasar Ekonometrika. Solo: Salemba Empat

H. Elkadhi Dan R. Hamida. (2014). The Short-Term Effects Of Air Popullation On Health In Sfax(Tunisia): An Ardl Cointegration Procedure, ICVE, 19-21

Margi, K. Dan Pendawa, W, S. (2015). Analisa Dan Penerapan Metode Single Exponential Smoothing
Untuk Prediksi Penjualan Pada Periode Tertentu, Jurnal Teknologi Informasi, 11(2), 12-20

Nuraini, R. (2015), Desain Algorithma Operasi Perkalian Matriks Menggunakan Metode Flowchart, Jurnal Teknik Komputer Amik BSI, 1(1), 144-151

Pakaja, F., Naba, A., Purwanto. (2012), Peramalan Penjualan Mobil Menggunakan Jaringan Syaraf Tiruan Dan Certainty Factor, Jurnal Eeccis, 6(1), 4555

Pratama, I. H. P., \& Saputro, D. R. S. (2018). Model Runtun Waktu Vector Autoregressive Moving Average With Exogenous Variable (VARMAX), KNPMP III, 490-497

Putra, E, A. (2015). Analisis Curah Hujan Bulanan Menggunakan Metode Eksponential Smoothing (Studi Kasus : Katulampa Bogor ), Departemen Geofisika Dan Meteorology Fakultas Matematika Dan Ilmu Pengetahuan Alam, Institut Pertanian Bogor. Bogor

Rosadi, Dedi. (2011). Analisis Ekonometrika \& Runtun Waktu Terapan Dengan R,Aplikasi Untuk Bidang Ekonomi, Bisnis, Dan Keuangan. Yogyakarta: C.VAndi Offset.

Sungkawa, I. Dan Megasari R.T. (2011). Penerapan Ukuran Ketetapan Nilai Ramalan Data Deret Waktu Dalam Seleksi Model Peramalan Volume Penjualan Pt Satriamandiri Citramulia. Jakarta: Binus University. 